etnografia, a declaração de um informante é especialmente interessante: "brincar é modo de dizer, porque o boi não brinca com ninguém" (:76). A declaração revela uma forma de empatia. Nesse caso, porém, ver a brincadeira do ponto de vista do outro é potencialmente perigoso, já que, para o boi, o jogo é de vida ou morte. O animal está inserido em uma experiência de risco vivida socialmente.

A partir daí, a festa popular é ligada pelo autor a uma visão de mundo primitivista, que remete a uma representação particular do sacrifício. O animal doméstico é primeiro solto para depois ser enfrentado, o que invoca uma lógica de caça uma ritualização do embate com o animal selvagem que se tornará alimento.

A relação farrista com o boi envolve comer e brincar, e é em função desse par de atitudes que se produz o choque entre a prática local e o universo urbano circundante. Nesse sentido, a polêmica em torno das representações do animal tem como ponto em comum o comer, e como diferencial o brincar: é entre jogo e sacrifício que se formula o conflito entre as duas visões.

MASSON, Laura. 2004. La política en femenino. Género y poder en la provincia de Buenos Aires. Buenos Aires: Antropofagia. $140 \mathrm{pp}$.

\section{Andrea Lacombe}

Doutoranda do PPGAS/Museu Nacional/UFRJ

La política en femenino, de Laura Masson, pode ser lido à luz dos dois pontos que integram o título: uma etnografia dos $l u-$ gares políticos ocupados por mulheres em um tempo-espaço particular e conjuntural da cena política argentina, colocando-se, segundo a autora, em uma interseção "entre la Antropología de la política y la Antropología del Estado" (:15).
Originado como dissertação de mestrado defendida no PPGAS/MN/ UFRJ, este livro faz parte de uma coletânea, dirigida pelos antropólogos Rosana Guber (CONICET-IDES) e Federico Neiburg (PPGAS/MN/UFRJ), destinada a publicar etnografias inéditas.

Neste caso, a presente etnografia tenta dimensionar modos particulares em que as mulheres se integraram à vida política da província de Buenos Aires (Argentina), na década de 90 do século passado. Estes modos estiveram marcados por um discurso oficial que, contínua e incessantemente, explicitava o caráter "apolítico" das ações que elas realizavam. A pesquisa é desenvolvida tomando como pedra de toque as eleições legislativas nacionais de 1997, nas quais as listas eleitorais, na província de Buenos Aires, dos dois principais partidos políticos do momento - a Alianza e o Justicialismo - foram encabeçadas por mulheres (Graciela Fernández Meijide e Hilda González, respectivamente). A partir deste fato, a autora reconstrói de forma genealógica o caminho pelo qual a candidata do partido Justicialista chega a se constituir como tal. A importância deste percurso resultará na explicitação e na concretização de um modo de conceber a política, que será o fio condutor e o principal ponto de análise do livro.

Para a realização deste objetivo, a autora recorre ao estudo detalhado de três eixos básicos na construção do objeto: as instituições públicas, nas quais as mulheres operam; as leis e as políticas que as constituem; e o papel dos meios de comunicação na divulgação das ações que as ditas instituições desenvolvem, promulgando assim visões explícitas do que significa fazer política e ser mulher. Tais instituições foram o Consejo Provincial de la Mujer (CPM) que, posteriormente, foi convertido no Consejo Provincial de la Familia y Desarrollo Humano (CPFDH), ambas destinadas à ob- 
tenção de políticas de ação e de desenvolvimento social.

Com uma descrição densa e minuciosa, Masson consegue percorrer com sucesso um caminho intrincado em prol de compreender e de explicar os novos significados que a palavra política adquire neste contexto particular. Tal fim é efetivado ao longo do livro através do desenvolvimento dos eixos supracitados, em três momentos determinados que dão forma aos capítulos. Eles são as eleições legislativas de 1997, a transformação do CPM em CPFDH e a aparição de novas agentes dentro do campo político da província, a saber, as Conselheiras Executivas do $\mathrm{CPFDH}$ e as Manzaneras (nome derivado da distribuição espacial do trabalho: cada pessoa tinha sob seu cuidado uma determinada quantidade de quarteirões manzanas em espanhol — onde distribuir alimentos e cuidar do bem-estar dos habitantes dessa área). Desta maneira, a autora tenta reconstruir os diversos modos com que as identidades femininas se apresentam no campo da política e quais as estratégias utilizadas pelos diversos atores para legitimarem a ideologia que sustentam.

Assim, o primeiro capítulo é dedicado "a la construcción de las identidades femeninas que caracterizaron a las candidaturas de Hilda González y Graciela Fernández Meijide y la participación de la prensa en la construcción del campo político" (:25), analisando tanto as estratégias de apresentação de ambas quanto os modos pelos quais a imprensa as retrata. As candidatas aparecem representando duas visões diferenciadas com relação à idéia de mulher. Mesmo sem pertencer ao campo da política, elas o apreendem a partir de modos particulares que representam duas instâncias específicas da história política argentina e constroem estratégias particulares com relação ao habitus de suas próprias classes e dos eleitores-alvo.
Hilda González é retratada tendo em conta a "combinación de elementos emblemáticos del Partido Justicialista y la reivindicación de roles femeninos tradicionales" (:25). Reificando a mítica figura de Eva Perón, por um lado, e defendendo os valores morais da família cristã, por outro, legitima sua posição no campo da política, no seu habitus de classe e no pertencimento a uma família singela interiorana, na qual os filhos devem ser a principal razão de viver de uma mulher. Sem esquecer, claro, que era a esposa do governador de Buenos Aires no momento: Eduardo Duhalde.

Da sua parte, a candidata da Alianza, Graciela Fernández Meijide, proveniente de camadas médias, fundamenta sua participação na política pela desaparição de um filho durante a ditadura militar, motivo que suscitou a necessidade de se fazer ativamente presente na política em organizações de familiares de desaparecidos. Seu marido não tem relação com a política, sendo individual a sua entrada neste campo.

Mesmo assim, é a imprensa que as coloca como antípodas, duas opções políticas antitéticas para os eleitores já que, além das particularidades pessoais, os partidos políticos aos quais elas pertencem têm sido historicamente bipolares (devo lembrar que a Alianza estava formada pelo Partido Radical, rival histórico do Justicialismo, e o Frente de País Solidário FREPASO, de recente formação).

A estrutura argumentativa desenvolve dedutivamente os desprendimentos dos dois ideários de mulher apresentados pela autora. Fica claro que a apresentação da candidata da Alianza funciona só como contraponto analítico ao ideário de [mulher] política que será desenvolvido ao longo do texto. Assim, a partir da figura de Hilda González, esboçada como paradigma de mulher tradicional, Masson consegue explicar a moral subjacente às políticas sociais aplicadas aos organismos que ela investiga 
no segundo capítulo e à concepção e aos modos de capacitação das manzaneras explicitados no último capítulo.

Os dois últimos capítulos podem ser lidos a partir da mesma ótica de análise, como uma estrutura genealógica que converge na disputa eleitoral, objeto do primeiro. Neles se desenham os passos que se seguiram à conversão do CPM em CPFDH presididos ambos por Hilda González que aparece como o aparato político-estatal de assistencialismo social da província de Buenos Aires durante o governo de Eduardo Duhalde. As características marcantes desta mudança serão, em primeiro lugar, a linha ideológica do CPM e, logo depois, a desarticulação para convertê-lo em CPFDH. Deste modo, a linha política que imperara no CPM no governo anterior, a de considerar a mulher independentemente das relações de família ou matrimônio, dão lugar a uma outra, holística, que focaliza a mulher como parte integrante de um todo maior que se torna o eixo central das políticas da nova gerência: a família.

Em segundo lugar, a aparente "despolitização" do trabalho realizado no $\mathrm{CPFDH}$ desprende-se da consideração de pensar este mesmo trabalho como tarefas "naturalmente" feitas pelas mulheres, uma extensão dos afazeres de dona de casa, ergo, longe do "verdadeiro" métier da política reservado aos homens. Esta visão essencialista da mulher acavala-se com um modo de pensar a política "despolitizada", quer dizer, fora do âmbito da política tradicional, "muestra una de las maneras posibles de incorporar a las mujeres en la política" (:131) na Argentina. Este é um dos pontos mais importantes do aporte de Masson à interpretação da vida política desse país, ao enxergar uma forma híbrida entre o assistencialismo social de caridade, no melhor estilo Caritas, e a aplicação de políticas sociais planejadas a partir dos organismos estatais formados tanto por técnicos legitimados pelo seu capital simbólico adquirido através de títulos universitá- rios, quanto por mulheres cujo capital se baseia no ato de ser mulher. Tal modelo de política social "apolítica" convive com os modos tradicionais preexistentes de fazer política, entremeando as duas redes em uma luta de força e de poder, as quais entram em choque basicamente na hora de exibirem os resultados do trabalho em termos eleitorais.

Infelizmente, a intenção principal da autora de desconstruir as identidades genéricas desmancha-se e perde espaço para a análise, por demais impecável, da reconstituição do campo político a partir destas novas agentes. Ao longo da escrita, Masson parece perder o fio condutor que explicita como objetivo na introdução - a construção de identidades de gênero - tomando outro caminho que, segundo suas intenções, deveria permanecer em um plano menos visível: os novos modos de fazer política. A identidade feminina fica essencializada por trás da construção detalhada do novo caminho empreendido, que "pone en discusión y cuestiona el funcionamiento de formas hasta ese momento legítimas" (:12829) de fazer política na Argentina.

Resgatando uma etnografia da política e das instituições, lúcida e cuidadosa, talvez fosse necessário explorar ainda mais os meandros das conceitualizações de gênero, explicitando pressupostos teóricos a esse respeito para costurá-las com as visões de mulher e política presentes no texto.

SívORI, Horacio. 2005. Locas, chongos y gays. Sociabilidad homosexual masculina durante la década de 1990. Buenos Aires: Editorial Antropofagia. Serie Etnográfica. 119 pp.

\section{María Elvira Díaz Benítez.}

Doutoranda PPGAS/Museu Nacional/UFRJ

Esta etnografia é o resultado da dissertação de mestrado em antropologia que Horacio Sívori realizou na New York 